\title{
PROPOSTA DE UM REFERENCIAL METODOLÓGICO PARA A AVALIAÇÃO DE PROCESSOS DE LOGÍSTICA REVERSA DE PRODUTOS PÓS-VENDA EM EMPRESAS INDUSTRIAIS
}

\section{PROPOSAL OF A BENCHMARK METHODOLOGY FOR EVALUATION OF PROCESS OF REVERSE LOGISTICS OF AFTER SALES PRODUCTS IN INDUSTRIAL ENTERPRISES}

\author{
Andréia Marize Rodrigues ${ }^{1}$; Marcelo Giroto Rebelato ${ }^{2}$ \\ ${ }^{1}$ Universidade Estadual Paulista Júlio de Mesquita Filho - UNESP - Jaboticabal - SP - Brasil \\ andreiamarize@fcav.unesp.br \\ ${ }^{2}$ Universidade Estadual Paulista Júlio de Mesquita Filho - UNESP - Jaboticabal - SP - Brasil \\ mgiroto@fcav.unesp.br
}

\begin{abstract}
Resumo
Com vistas ao atendimento das novas demandas de mercado ou mesmo para acolher objetivos econômicos, as empresas têm buscado sua adequação ambiental a partir da mudança de seus sistemas produtivos rumo à adoção de tecnologias mais limpas e ao estudo dos impactos ambientais gerados por seus produtos. Desta forma, a reinserção de materiais no processo produtivo e o reaproveitamento de produtos pós-venda ou pós-consumo têm sido cada vez mais praticados. Para tanto, novas atividades administrativas passam a ser realizadas, destacando-se a Logística Reversa, que trata do planejamento, operações e sistemas de informação necessários à reutilização de materiais ou à destinação adequada de produtos retornados às empresas produtoras. Diante deste contexto, o objetivo deste artigo consiste na construção de um referencial metodológico qualitativo para a avaliação do desempenho de processos de Logística Reversa de "bens pós-venda" adotados por empresas industriais. Como resultado, o desenvolvimento do referencial metodológico considerou nove categorias de elementos relacionados aos retornos que possibilitassem a avaliação pretendida, sendo elas: produtos; processos; mecanismos de entrada; mecanismos de coleta; mecanismos de recepção, separação e armazenagem; mecanismos de processamento dos retornos; sistema de disposição; sistemas de informação; e sistema de coordenação. Para exemplificação da aplicação do referencial metodológico proposto, foi realizada uma pesquisa em uma empresa do setor químico que apresentou satisfação em 77,2\% dos elementos considerados.
\end{abstract}

Palavras-chave: logística reversa; bens pós-venda; desempenho; indústria.

\section{Introdução}

O impacto ambiental total de um produto tem início com a extração de matérias primas, podendo igualmente ser notado seu efeito sobre o meio ambiente ao longo de todas as suas fases de processamento, produção, embalagem, transporte, consumo e descarte, ressaltando a necessidade dos sistemas produtivos adotarem cuidados ambientais em todo o ciclo de vida de seus produtos 
(KINLAW, 1997; EL KORCHI e MILLET, 2011). Entende-se, assim, que para não haver comprometimento das condições ambientais do planeta, torna-se necessário que as empresas industriais trabalhem em processos que consigam aproveitar e destinar corretamente seus produtos desde a sua produção até depois de consumidos pelo cliente, ou seja, ao final de sua vida útil.

Neste sentido, atividades da recuperação de produto tais como a reciclagem, o recondicionando e a reutilização está se tornando partes integrais das cadeias de suprimentos da fabricação (BARKER e ZABINSKI, 2011). Deste modo, a coleta de produtos pós-venda ou pósconsumo, seja para sua reintrodução ao processo produtivo visando seu aproveitamento ou para que seja efetuado seu descarte apropriado necessita ser gerenciada. Neste contexto, destaca-se a Logística Reversa, definida por Rogers e Tibben-Lembke (1999) como "processo de planejamento, implementação e controle eficiente do fluxo de matérias-primas, estoque em processo, produtos acabados e informações correspondentes, do ponto de consumo para o local de origem, com o propósito de recapturar valor ou adequar o seu destino".

A Logística Reversa tem se destacado nos últimos anos em função de seu grande potencial em resolver problemas ambientais comuns nas empresas, tais como a destinação de resíduos e reciclagem e reaproveitamento de materiais (XAVIER et al, 2004; WU e CHENG, 2006; MOLLENKOPF e CLOSS, 2005). No entanto, apesar de diversos textos publicados na área, a literatura e teoria holística disponíveis no desenvolvimento de um sistema de Logística Reversa é ainda limitada. Em geral, a literatura e os recursos relacionados encontrados nesta área geralmente não possuem visão em profundidade no que diz respeito aos processos necessários para a construção deste tipo de sistema (LAMBERT et al, 2011; BARKER e ZABINSKY, 2008). Para Rodrigues et al (2012), Chaves et al (2008) e Chaves et al (2011) a ausência de indicadores para esta atividade contribui substancialmente para isso uma vez que assim como em outros processos de uma empresa, o mapeamento e a análise de processos de Logística Reversa podem ser úteis tanto para a promoção de melhorias em seu desempenho quanto para a descoberta e divulgação de boas práticas que podem ser adotadas por outras empresas com processos semelhantes.

Neste contexto, este artigo tem por objetivo a construção de um referencial metodológico qualitativo específico para a avaliação do desempenho de processos de Logística Reversa de bens pós-venda adotados por empresas industriais.

Para atender ao objetivo proposto, este texto encontra-se estruturado em sete tópicos, a contar com esta introdução. O próximo tópico (tópico 2) descreve o plano de trabalho e a metodologia adotados. Já o tópico 3 traça um panorama acerca das características do ambiente dos negócios com a ascensão da variável ambiental e são feitas definições relacionadas ao conceito de Logística Reversa. O tópico 4 apresenta mecanismos de avaliação do desempenho de processos logísticos reversos e as principais dificuldades encontradas pelas empresas em sua implementação e 
manutenção. O referencial metodológico desenvolvido é apresentado e discutido no tópico 5 . No tópico 6 é apresentado um exemplo de aplicação do referencial proposto e, por fim, o tópico 7 traça as considerações finais do trabalho.

\section{Metodologia de desenvolvimento}

Este trabalho é caracterizado como uma pesquisa exploratória, teórica de caráter qualitativo. A partir de revisão bibliográfica foram determinadas as premissas para a construção de um referencial metodológico qualitativo visando à avaliação de desempenho de processos logísticos reversos de bens pós-venda em empresas do segmento industrial. Para tanto, este trabalho foi desenvolvido em quatro etapas, descritas a seguir:

- Etapa 1: Revisão bibliográfica sobre Logística Reversa e mecanismos qualitativos de avaliação de processos de Logística Reversa;

- Etapa 2: Levantamento dos principais aspectos considerados pelos autores que podem ser utilizados para a análise de processos logísticos reversos;

- Etapa 3: Síntese dos principais aspectos levantados a partir dos autores pesquisados e construção do referencial metodológico;

- Etapa 4: Aplicação do referencial metodológico desenvolvido em uma empresa industrial, selecionada pelo critério conveniência, na qual foram realizadas entrevistas com os gerentes das áreas de produção e de logística.

\section{Logística reversa: definições e características}

Ao longo da década de 1980, com o intenso interesse sobre temas ecológicos, pesquisadores da área de produção e operações passam a abordar a logística adaptando-a aos conceitos ambientais, surgindo assim o conceito de Logística Reversa (XAVIER et al, 2004).

A Logística Reversa trata dos aspectos de planejamento, operação de fluxo e sistemas de informações do retorno de produtos, materiais ou embalagens ao centro produtivo por meio de diversos canais reversos, agregando-lhes valores de diversas naturezas.

Para Stock (1998), a Logística Reversa representa o papel da logística no retorno de produtos, na redução de uso de matéria-prima virgem, no uso da reciclagem, na substituição de materiais, na reutilização de materiais, na disposição de resíduos, no recondicionamento, no reparo e na remanufatura de produtos. Desta maneira, Ravi e Shankar (2005) destacam a relevância da Logística Reversa tanto na recapturação de valor econômico a partir do reaproveitamento de materiais quanto no objetivo de preservação do meio-ambiente.

Uma visão mais abrangente do conceito de Logística Reversa é adotada por Leite (2009, 
p.17), definindo-a como a extensão da logística empresarial que se responsabiliza pelo planejamento, pela operação e pelo controle do fluxo de informações logísticas correspondentes, “do retorno dos bens de pós-venda e de pós-consumo ao ciclo de negócios ou ao ciclo produtivo, por meio dos canais de distribuição reversos, agregando-lhes valor de diversas naturezas: econômico, ecológico, legal, logístico, de imagem corporativa, entre outros."

Os canais de distribuição reversos se constituem nas formas e meios em que os produtos pós-consumo e pós-venda retornam ao ciclo produtivo ou de negócios, readquirindo valor em mercados ditos secundários pelo reuso ou pela reciclagem de seus constituintes (LEITE, 2009; EL KORCHI e MILLET, 2011).

Rogers e Tibben-Lembke (1999) ressaltam que a preocupação com o fluxo reverso de produtos em uma cadeia produtiva é bastante comum em algumas empresas, tais como o fluxo de embalagens dos pontos de venda às fábricas em empresas fabricantes de bebidas e o fluxo de sucata gerada pelos clientes que retornam às siderúrgicas como parte de seus insumos de produção.

Desta maneira, a Logística Reversa amplia o conceito tradicional de logística além da distribuição em si, pois a vida dos produtos não termina somente quando o mesmo é entregue ao cliente; ela tem sua continuidade ainda depois dos produtos serem vendidos ou consumidos.

\subsection{Ciclo de vida dos produtos e razões dos retornos}

Para desenvolver a rede de distribuição reversa e saber qual o destino a ser dado a cada material coletado, é preciso conhecer aspectos importantes de seu ciclo de vida, citados por Leite (2009) como as características de um bem:

- Durável: produto que pode ser utilizado diversas vezes, estando sua vida útil entre dois anos e algumas décadas;

- Semidurável: produto que pode ser utilizado diversas vezes, mas sua vida útil não ultrapassa dois anos;

- Descartável: Produtos que se utiliza apenas uma vez ou por apenas algumas semanas.

O retorno de produtos pode ter sua ocorrência calcada em diversas razões. De Britto e Decker (2002; 2003) e Rogers e Tibben-Lembke (1999) discutem este motivos dividindo-os em três categorias principais, a saber:

a) Retornos das etapas produtivas: nesses casos os componentes ou produtos têm de ser recuperados ainda na fase de produção. Isso ocorre por uma série de razões como sobras de matérias-primas e de produção e falhas de qualidade em produtos em processos (defeituosos).

b) Retornos de distribuição: referem-se a todos os retornos que são iniciados por um ator da cadeia de abastecimento durante a distribuição depois que o produto foi feito (incluindo o 
fabricante). Nesta categoria estão: recalls, retornos comerciais, retornos de distribuição e retornos funcionais.

c) Retorno de clientes/consumidores: este terceiro grupo é composto por devoluções iniciadas pelo cliente. Nesta categoria também há uma variedade de razões para a devolução de produtos, como garantias de reembolso, garantia do produto, serviço (reparos e reposição de peças), produto em fim de uso ou em fim de vida útil.

\section{2. Áreas de atuação da logística reversa}

Para Leite (2009), a atuação da Logística Reversa pode ser visualizada duas grandes áreas que fazem acontecer o fluxo reverso: primeira delas trata de bens de pós-venda e a segunda área de bens de pós-consumo. Alguns autores, como Liva et al (2003) ainda consideram as embalagens como uma terceira área de atuação e RODRIGUES et al (2009) propõem a consideração da logística reversa relativa aos resíduos internos da empresa:

a) Logística reversa de bens pós-venda: bens de pós-venda são caracterizados pelo pouco ou nenhum uso, que podem retornar aos diferentes elos da cadeia produtiva devido a defeitos, avarias do transporte, manutenções e consertos, prazo de validade, garantia dada pelo fabricante, falta de estoque, recall, erros no processamento dos pedidos, dentre outros. Este retorno geralmente está vinculado à qualidade do produto e a questões comerciais e substituição de componentes (LEITE, 2009);

b) Logística reversa de bens pós-consumo: bens de pós-consumo são aqueles em fim de vida útil ou usados com possibilidade de reutilização e os resíduos industriais em geral. Estes bens poderão se originar de bens duráveis ou descartáveis, que podem ser destinados ao reuso ou desmanche, tendo a chance de serem remanufaturados e após o processo de desmanche poderão ser destinados à reciclagem ou à disposição final em aterros sanitários, lixões ou sofrerem incinerações (LEITE, 2009);

c) Logística reversa de embalagens: as embalagens se mostram tão importantes que existem pesquisadores que as classificam em uma categoria distinta. Isto se deve à tendência mundial de se utilizar embalagens retornáveis, reutilizáveis ou de múltiplas viagens, tendo em vista o aumento dos resíduos totais verificado a cada ano, ocasionando impactos negativos ao meio ambiente (LIVA et al, 2003);

d) Logística reversa interna: relacionada ao reaproveitamento e/ou destinação adequada dos materiais e resíduos gerados nas etapas do processo produtivos, se constituindo em um típico caso da fronteira entre a Logística Reversa e a Gestão de Resíduos (RODRIGUES et al, 2009).

Esta distinção da Logística Reversa por características dos produtos faz-se importante pelo fato dos canais de distribuição reversos pelos quais estes bens fluem serem normalmente diversos. 
Esta divisão possibilita o trabalho específico para cada uma das classificações, gerando objetivos estratégicos e o uso de técnicas operacionais distintas para cada uma das áreas (RODRIGUES et al, 2002; LEITE, 2009). Porém, é importante observar que os sistemas reversos podem se entrelaçar devido à multiplicidade de possibilidades de comercializações e processamentos nas etapas reversas. Os produtos de pós-venda retornam através da própria cadeia de distribuição direta, tendo, em geral, como origem do retorno um dos elos da cadeia ou o próprio consumidor final e como destino o fabricante do produto. Já os bens pós-consumo normalmente tendem a ser recuperados a partir de mercados secundários, responsáveis por sua recuperação e revenda (LEITE, 2009; STOCK, 1998; ROGERS e, TIBBEN-LEMBKE, 1999).

\section{Mecanismos de avaliação de processos de logística reversa}

É possível encontrar na literatura trabalhos que sugerem parâmetros para auxiliar a avaliação do desempenho de processos de Logística Reversa. A maioria destes trabalhos, no entanto, sugere elementos específicos para o auxílio na estruturação de redes logísticas que cuidam do fluxo reverso, sendo possível a partir destes elementos traçar uma avaliação dos processos de Logística Reversa adotados por uma empresa.

De acordo com Barker e Zabinski (2008), a maior parte das pesquisas sobre como estruturar redes logísticas reversas tem se concentrado em um determinado produto ou setor, sendo ainda poucos trabalhos que traçam um panorama mais amplo, visando resolver o caso geral de Logística Reversa em todos os produtos e indústrias. Uma outra característica destes trabalhos apontada por estes autores está na divisão dos estudos em estruturação de redes logísticas reversas em estudos quantitativos e estudos qualitativos. Na linha quantitativa estão estudos baseados na utilização de modelos de programação linear para o desenho de rede e, mais recentemente, os modelos começaram a incorporar a programação estocástica e abordagens de otimização robusta para resolver as incertezas em qualidade e quantidade de produto retornado. Já na vertente qualitativa, Barker e Zabinski (2008) destacam trabalhos que abordam parâmetros e características que devem possuir as redes e processos logísticos reversos que garantiriam seu a eficiência de seu funcionamento.

A seguir encontram-se descritos trabalhos de cunho qualitativo cujos parâmetros mostram-se passíveis de utilização para avaliação de processos logísticos reversos.

\subsection{Os elementos de Lambert et al (2011)}

Os autores propõem uma estrutura abrangente na qual são elencados sete importantes elementos da Logística Reversa. A estrutura proposta destaca o relevante papel da comunicação na 
coordenação e gestão do processo logístico reverso. Os elementos desta proposta estão descrito a seguir:

a) Sistema de coordenação: versa sobre a necessidade da supervisão integral do sistema logístico reverso, sendo o sistema de coordenação responsável pelo desempenho global e pela administração de todos os processos ligados à Logística Reversa da empresa. É ressaltada a importância do vínculo deste sistema de coordenação aos níveis hierárquicos superiores da empresa;

b) Entrada: elemento identificado quando do pronunciamento por parte do cliente pela necessidade do retorno de um produto à empresa. A partir deste momento é que inicia a decisão sobre quais produtos estão em condições de entrar no sistema logístico reverso e quais devem ser rejeitados devido à impossibilidade de reutilização. A empresa pode oferecer aos clientes serviço de assistência técnica objetivando, inclusive, a identificação do problema com o produto antes seu retorno;

c) Coleta: elemento descrito em duas etapas: a) captação de produtos e b) transporte. A responsabilidade por estas atividades pode ser da própria empresa, do cliente ou de um terceiro elemento, a depender de fatores como a complexidade do produto, a razão do retorno, as localidades envolvidas, dentre outros;

d) Separação/triagem: para produtos reutilizáveis, é feita uma análise para que não haja discrepâncias com relação ao que foi determinado no momento em que o produto foi aceito no processo reverso;

e) Processamento/tratamento: atividades de planejamento do tratamento que será dado ao produto - reciclagem, reintrodução ao processo produtivo, descarte, entre outras opções. Estas opções devem ser avaliadas de acordo com diversos fatores que devem ser avaliados conjuntamente;

f) Sistema de informação: integração e interação entre todos os elementos do sistema logístico reverso, visando ao gerenciamento de dados como quantidades de estoques e planejamento da produção, envolvendo ainda o fornecimento de informações sobre a satisfação do cliente com relação ao produto;

g) Sistema de disposição: envolve as saídas do sistema logístico reverso, ou seja, trata da destinação final dos produtos coletados. Dentre as opções da empresa com relação ao produto estão a decisão de não fazer nada a respeito do retorno, de enviar o produto novamente ao cliente ou de enviá-lo um produto substituto, dentre outras.

\subsection{A estrutura teórica de Genchev et al (2011)}

Estrutura teórica para avaliação de programas baseada em seis aspectos de um processo de Logística Reversa e suas atividades relacionadas, quais sejam: 
a) Início dos retornos: processo no qual o cliente solicita a aprovação a respeito do retorno do produto ou o envia diretamente ao centro de coleta. A política e as rotinas que regem os retornos devem ser claras sendo fundamental a participação dos clientes neste processo;

b) Determinação da destinação: determina o modo de transporte e a destinação do produto devolvido devendo, para isso, serem estabelecidas e formalizadas as diretrizes de envio;

c) Recebimento: inclui atividades como verificação, inspeção e processamento do produto devolvido, tendo em vista a importância da eficiência desta etapa;

d) Disposição: compreende a escolha da disposição do produto (retorno ao cliente, retorno ao estoque, renovação, revenda, doação, liquidação, rejeição);

e) Tratamento ao cliente: com foco na satisfação do cliente, faz-se necessária uma política de retorno clara, e um serviço pós-venda de qualidade. Aqui são tomadas ações relativas à realização de reembolsos e a possíveis negociações financeiras entre a empresa e o cliente;

f) Análise dos retornos e mensuração da performance: esta última etapa consiste no processo de análise dos retornos e da mensuração do desempenho do sistema logístico reverso.

\subsection{Os parâmetros de De Britto e Decker (2002; 2003)}

Estes autores sugerem que os processos relacionados à Logística Reversa sejam analisados a partir de quatro parâmetros:

a) Por que os bens retornam: envolve as motivações para a adoção de processos logísticos reversos (benefícios auferidos aos envolvidos pelo retorno, obrigações ambientais ou legais, ou motivação social) e as razões do retorno dos produtos (retornos das etapas produtivas, retornos de distribuição e retornos de clientes/consumidores);

b) que está retornando: identifica quais materiais estão no processo e quais de suas características fazem com que sejam interessantes para o reaproveitamento ou que fazem com que esse produto seja descartado. Dentre estas características estão: composição do produto, padrão de uso do produto e deterioração (perecibilidade) do produto. A partir destas características pode-se determinar a possibilidade e/ou viabilidade da reciclagem e de contaminação do meio ambiente após o descarte;

c) Como são os processos da Logística Reversa: são definidos quais os canais de distribuição reversos e de que forma eles são organizados. Dentre os estágios logísticos reversos estão: coleta, classificação/testes, processamento e redistribuição. Inserem-se ainda neste parâmetro a definição da destinação dos materiais coletados: revenda, redistribuição, reparo, reforma, remanufatura, recuperação, reciclagem, descarte adequado ou incineração;

d) Quem está envolvido no processo: é possível definir como a Logística Reversa funciona na prática a partir da escolha dos atores e de seus papéis nos estágios do processo logístico reverso. 
Assim, este parâmetro se relaciona com os sujeitos que participam dos canais reversos e de que forma eles participam do processo. Os atores podem ser separados em devolutores, receptores e processadores dos produtos retornados.

\subsection{Fatores de Lacerda (2002)}

O autor destaca que a eficiência alcançada em um processo de Logística Reversa depende de seu planejamento e controle. Eis os fatores que podem contribuir positivamente para o seu desempenho:

a) Bons controles de entrada: identificação correta do estado dos materiais que retornam com a finalidade de destiná-los ao reverso adequado, quais sejam: revenda, recondicionamento, reciclagem ou descarte. $\mathrm{O}$ autor argumenta que a identificação apropriada evita retrabalhos ou atritos entre fornecedores e clientes pela falta de confiança em relação às causas dos retornos;

b) Processos padronizados e mapeados: a Logística Reversa não deve ser tratada de forma esporádica, e sim regular, sendo que seus processos devem ser corretamente mapeados e os procedimentos formalizados para que haja o controle e a obtenção de melhorias;

c) Tempo de ciclo reduzidos: refere-se ao tempo entre a identificação da necessidade de reciclagem, disposição ou retorno de produtos e seu efetivo processamento; ciclos longos atrasam a geração de caixa para a empresa além de ocupar espaço de estoque;

d) Sistemas de informação: construção ou aquisição de sistemas de informação possibilitem o rastreamento de retornos, medição dos tempos de ciclo e medição do desempenho de fornecedores disponibilizando informações para negociação, melhoria de desempenho e identificação de possíveis abusos dos consumidores no retorno de produtos;

e) Rede logística planejada: assim como no processo logístico direto, a implementação da Logística Reversa demanda uma infraestrutura logística adequada para lidar com os fluxos de entrada de materiais usados e fluxos de saída de materiais processados;

f) Relações colaborativas entre clientes e fornecedores: como existem muitas devoluções que são feitas em função de produtos danificados, é necessária uma relação de confiança e colaboração entre varejistas e indústrias, a fim de que ninguém se sinta lesado na transação.

\subsection{Constructo de Leite et al (2005)}

Os autores reuniram vários parâmetros relacionados em uma matriz, chamada de "matriz de estruturação de canal reverso", desenvolvida para ser utilizada como um constructo de medida do nível de organização do canal reverso. Estes parâmetros foram divididos em seis categorias principais, ilustradas no Quadro 1. Cada aspecto apontado no quadro foi examinado a partir da 
constatação de sua existência e, visando tornar a medida mais objetiva, foi avaliada sua intensidade em uma escala de três níveis, ou seja, de 1 a 3.

Quadro 1 - Aspectos observáveis na estruturação de canais reversos

\begin{tabular}{|c|c|}
\hline CATEGORIA & ASPECTOS \\
\hline PROCEDIMENTOS GERAIS & $\begin{array}{l}\text { - Procedimentos de retorno definidos } \\
\text { - Controle do recebimento de retornos } \\
\text { - Classificação e quantidades do retorno } \\
\text { - Codificação do retorno por controles } \\
\text { - Procedimentos de consolidação do retorno } \\
\text { - Procedimentos de seleção e destinos definidos }\end{array}$ \\
\hline ARMAZENAGEM E RECURSOS & $\begin{array}{l}\text { - Áreas específicas destinadas ao retorno } \\
\text { - Áreas específicas destinadas à remanufatura } \\
\text { - Controle dos custos de armazenagem do retorno } \\
\text { - Pessoal dedicado ao retorno } \\
\text { - Equipamentos dedicados ao retorno } \\
\text { - Sistemas de informação dedicados ao retorno }\end{array}$ \\
\hline TRANSPORTE & $\begin{array}{l}\text { - Meios e veículos definidos } \\
\text { - Freqüência e trajeto de coleta definidos } \\
\text { - Acondicionamento definido do retorno } \\
\text { - Prioridade do retorno } \\
\text { - Controle de custos de transporte do retorno }\end{array}$ \\
\hline REVALORIZAÇÃO & $\begin{array}{l}\text { - Motiva o tratamento do retorno } \\
\text { - Proporciona ganhos de imagem } \\
\text { - Proporciona recuperação de valor } \\
\text { - Custo e receita conhecidos } \\
\text { - Existência de mercados secundários definidos }\end{array}$ \\
\hline CONTRATOS & $\begin{array}{l}\text { - Existência de contratos de retorno na cadeia } \\
\text { - Há terceiros contratados para a revalorização } \\
\text { - Há fluxo de pagamentos e ressarcimentos }\end{array}$ \\
\hline FLUXO DE INFORMAÇÕES & $\begin{array}{l}\text { - Há sistema de informação para o retorno } \\
\text { - Operações são informatizadas } \\
\text { - Informações alimentam outras áreas }\end{array}$ \\
\hline
\end{tabular}

Fonte: LEITE et al (2005)

\subsection{Parâmetros de Leite e Zamith (2005)}

Os referidos autores construíram um questionário contendo dez sentenças diretas de múltipla escolha para ser utilizado como instrumento de coleta de dados para pesquisa de processos logísticos reversos. Os aspectos focados pela pesquisa estão a seguir relacionados:

a) Setor econômico: os autores justificam que a inclusão deste tema na pesquisa deve-se ao fato das taxas de retorno de produtos variam fortemente entre os diferentes setores industriais;

b) Posição no canal de distribuição: para os autores, a literatura consultada destaca diferentes níveis de poder de barganha e de políticas empresariais relativos à Logística Reversa em empresas varejistas, distribuidoras ou fabricantes;

c) Tempo de vida útil dos produtos: o tema foi adotado em função de melhor entender a amostra da pesquisa e pela suposição de que este fator propicia diferentes níveis de reação empresarial;

d) Atitudes empresariais relativas ao retorno dos produtos; 
e) Objetivo estratégico principal visado pela empresa no tratamento do retorno: sua inclusão se deve à variedade de motivações do retorno de produtos;

f) Resultado proporcionado pelo retorno de mercadorias: segundo os autores, esta sentença visa avaliar o impacto do fluxo reverso sobre o lucro da empresa;

g) Custo relativo da Logística Reversa sobre os custos totais da logística na empresa: este item objetivou o conhecimento da relação entre os custos logísticos e as variações face às demais variáveis da pesquisa;

h) Destino dado aos produtos retornados: esta sentença objetivou identificar como as empresas estão tratando a recaptura de valor dos bens retornados;

i) Terceirização das atividades de logística reversa;

j) Tempo de ciclo médio de devolução: os autores argumentam que o tempo de retorno está associado à desvalorização dos bens e à eficácia no tratamento dos produtos retornados.

\subsection{Barreiras e desafios da logística reversa (Ravi e Shankar, 2005)}

Apesar de as práticas relacionadas à Logística Reversa terem auxiliado as causas de proteção ao meio ambiente, a aplicação de suas abordagens enfrenta algumas barreiras, a saber:

a) Falta de sistemas de informação e de tecnologia: A Logística Reversa necessita do apoio de um eficiente sistema de informação e tecnologia durante os diferentes estágios do ciclo de vida de um produto, como na fase de desenvolvimento do produto, quando importantes variáveis devem ser consideradas, como, por exemplo, o material usado na fabricação e a estrutura do produto;

b) Problemas com a qualidade do produto: A condição de qualidade em que se encontram os produtos retornados também é considerada uma barreira à Logística Reversa já que esta não é uniforme. Isso se torna um problema para os fabricantes, uma vez que os consumidores geralmente esperam um alto nível de qualidade dos produtos independentemente da sua origem;

c) Políticas empresariais: Políticas empresariais restritivas tornam-se uma barreira à Logística Reversa. As empresas buscam criar uma boa imagem junto ao consumidor, porém temem pôr em risco a qualidade do produto final em decorrência do uso de materiais retornados;

d) Resistência a mudanças: Principal barreira observada na implementação da Logística Reversa, de modo que demanda uma mudança radical na mentalidade e nas práticas tanto das pessoas quanto das empresas. A falta de conhecimento a respeito dos benefícios da Logística Reversa é outro fator contribuinte para esta barreira, somado ao alto investimento inicial necessário para a utilização de um sistema reverso;

e) Falta de padrões de desempenho adequados: A mensuração do desempenho é um elemento essencial em qualquer sistema, por dar suporte aos processos de gestão e melhoria; 
f) Falta de treinamento e conscientização: A deficiência em recursos humanos é uma grande barreira a uma prática adequada da Logística Reversa. Instrução e treinamento, em todos os níveis hierárquicos, são requisitos primordiais para a obtenção do sucesso em qualquer organização;

g) Restrições financeiras: Restrição financeira é uma notável barreira a um bom programa de Logística Reversa e essencial para dar suporte aos seus requisitos de infraestrutura e mão-de-obra, tal aquisição de sistemas de informação e tecnologia e de treinamento de pessoal;

h) Falta de comprometimento da alta gerência: o comprometimento da alta gerência é o maior impulsionador dos empreendimentos corporativos. Uma liderança eficiente é necessária para fornecer visão e valores claros para os programas de Logística Reversa;

i) Pouco conhecimento sobre Logística Reversa: As empresas vêm observando um aumento no retorno de produtos. Dessa maneira, passa a ser uma questão de grande importância para as empresas o gerenciamento desse retorno, tanto de partes quanto de produtos inteiros, à cadeia de suprimento. A implementação da Logística Reversa pode trazer benefícios econômicos e ambientais, portanto, o pouco conhecimento a seu respeito torna-se uma barreira à mesma;

j) Falta de planejamento estratégico: O planejamento estratégico é fundamental para que as metas de sobrevivência da organização sejam atingidas com a implementação da Logística Reversa. Agora mais do que nunca, a economia e o comércio eletrônico estão demandando que as empresas tornem a Logística Reversa parte do seu arsenal de planejamento estratégico, identificando suas metas e especificando planos de logo prazo para atingi-las;

k) Relutância do apoio dos comerciantes, distribuidores e varejistas: No apoio às práticas de Logística Reversa, já que uma política de retorno de produtos liberal acarreta no aumento do compartilhamento dos riscos entre vendedores e consumidores.

\subsection{Os desafios de Grabara e Kot (2009)}

Poucas empresas têm estabelecido a Logística Reversa como uma atividade natural à sua logística tradicional e a maioria delas tem implantado soluções em resposta às imposições da legislação vigente. Desta maneira, de acordo com os autores, os maiores erros cometidos pelas empresas são:

a) Falta de abordagem de ciclo de vida do produto: muitos problemas na fase de recuperação são causados por um mau desenvolvimento do produto. Os processos de Logística Reversa devem ser concebidos em conjunto com a logística tradicional, fator que muitas vezes requer redefinição parcial dos processos logísticos tradicionais. Por outro lado, os processos logísticos reversos podem ser afetados fortemente pelos processos logísticos já existentes na empresa. Estender o serviço e melhorar a função, especialmente na fase de utilização, para melhorar eco-eficiência e reusabilidade; 
b) Otimização apenas de custos tangíveis: na Logística Reversa, ao lado dos custos "tangíveis", devem-se incluir também os chamados custos "intangíveis", como os custos de obsolescência e critérios de serviços relacionados. Este é de fato um princípio muito antigo. A importância dos efeitos tempo de espera tanto em custos e nível de serviço tem sido amplamente relatada na literatura de logística clássica;

c) Negligência da otimização da sustentabilidade: é necessário desenvolver e projetar produtos recuperáveis, que devem ser tecnicamente duradouros, utilizáveis por diversas vezes, sem causar danos ambientais, recuperáveis após o uso e compatíveis com o ambiente quando em fim de vida útil. Além disso, é importante adicionar o uso da energia de todo o sistema produtivo como um critério de otimização. Uma série de ferramentas de gestão, tais como a avaliação ambiental, análise de ciclo de vida, métodos ambientais de contabilidade como também os princípios de logística podem ajudar a empresa a identificar e selecionar as oportunidades de melhoria.

\subsection{Planejamento de processos de logística reversa (Barker e Zabinski, 2008)}

Convencionalmente, o planejamento das redes de cadeias de suprimento logísticas é determinado por categorias ou fases de tomadas de decisões: Com relação à Logística Reversa propriamente dita, os autores consideram quatro fases: conceitual, estratégica, tática e operacional. $\mathrm{Na}$ chamada fase conceitual são tomadas as providências iniciais do projeto, iniciando-se pela filosofia de retorno de produtos a ser adotada e pela definição de características dos componentes e do desenho de cada produto visando facilitar seu retorno e viabilizar seu descarte adequado ou reaproveitamento. Nesta fase o Ecodesign pode ser amplamente empregado. Já na fase estratégica são tomadas providências infraestruturais e de longo-prazo, tais como a decisão sobre a localização de instalações de recebimento e recuperação de produtos como também decisões como se o produto será reaproveitado pela própria empresa ou por empresas terceirizadas.

A fase tática, por sua vez, trata de decisões com um horizonte de médio-prazo, estando entre elas a definição dos processos de retorno e coleta de produtos. Por fim, é na fase de decisões ditas operacionais que são feitas definições relacionadas à operacionalização dos processos reversos, tais como definições de tamanho de lote de devolução e decisões quanto a forma mais adequada pata o transporte.

O Quadro 2 descreve essas quatro categorias e lista exemplos de decisões de Logística Reversa para cada fase.

Quadro 2 - Fases de decisão da cadeia de suprimentos reversa

\begin{tabular}{|c|l|}
\hline Fases de decisão & \multicolumn{1}{c|}{ Decisões relativas à Logística Reversa } \\
\hline $\begin{array}{c}\text { Fase Conceitual } \\
\text { Decisões iniciais do planejamento do produto }\end{array}$ & $\begin{array}{l}\text { - Filosofia de retorno de produtos } \\
\text { - Composição de materiais e design para } \\
\text { desmontagem/melhoramentos }\end{array}$ \\
\hline Fase Estratégica & $\begin{array}{l}\text { - Localização e capacidade das instalações } \\
\text { - Despesas }\end{array}$ \\
\hline
\end{tabular}




\begin{tabular}{|c|c|}
\hline decisões de infra-estrutura & $\begin{array}{l}\text { - Atividades/funções de recuperação } \\
\text { - Atividades próprias ou terceirizadas }\end{array}$ \\
\hline $\begin{array}{l}\text { Fase Tática } \\
\text { Decisões com um horizonte de tempo de três meses a um } \\
\text { ano, normalmente decisões de procedimentos para } \\
\text { maximizar de valores }\end{array}$ & $\begin{array}{l}\text { - Alocação de fluxos } \\
\text { - Previsões } \\
\text { - Ajustes às atividades de recuperação } \\
\text { - Mercados e escalas das atividades de recuperação } \\
\text { - Processos de retorno e coleta } \\
\text { - Definição e controle dos objetivos de recuperação }\end{array}$ \\
\hline $\begin{array}{c}\frac{\text { Fase Operacional }}{\text { Decisões do dia-a-dia com um horizonte de tempo }} \\
\text { semanal ou diário }\end{array}$ & $\begin{array}{l}\text { - Atender encomendas de consumidores pela recuperação } \\
\text { de produtos } \\
\text { - Atender os objetivos de recuperação } \\
\text { - Definição de tamanho do lote } \\
\text { - Decisões sobre transporte e expedição }\end{array}$ \\
\hline
\end{tabular}

Fonte: Barker e Zabinsky, 2008

\subsection{As estratégias de logística reversa de Giacobo et al (2003)}

Para os autores, uma vez implementados os processos logísticos reversos de uma empresa, a definição de estratégias específicas para a Logística Reversa pode ser feita pela utilização de uma sistemática composta por sete etapas, a saber:

a) Coletar informações sobre processos reversos da empresa: esta etapa inicial tem por objetivo a averiguação de como o processo logístico reverso atual está sendo realizado, quais resultados estão sendo alcançados e quais os custos associados. Ainda é possível verificar se o processo já apresenta algum resultado positivo, como, por exemplo, gerar receita para a empresa;

b) Identificar necessidades de clientes: a partir de pesquisas de satisfação junto aos clientes busca-se identificar quais suas necessidades e expectativas ao valer-se do serviço de retorno de produtos de sua residência ou empresa para o fornecedor;

c) Identificar ações da concorrência: a avaliação dos processos utilizados por empresas com desempenho apreciável no processo de Logística Reversa pode trazer ensinamentos e contribuições para a elaboração de atividades a serem realizadas. Com este benchmark a empresa pode obter ganhos tanto econômicos quanto em tempo uma vez que os erros cometidos pela concorrência podem ser evitados;

d) Verificar a viabilidade do serviço: esta se constitui em uma etapa crucial deste processo já que uma nova atividade que não traga incrementos na rentabilidade tanto econômica quanto estratégica para a empresa pode ser considerada como inviável e inapropriada;

e) Posicionar a administração sobre o serviço: aqui é efetuada a conscientização da administração e dos acionistas da empresa acerca da nova atividade. É fundamental o apoio de todos os membros da organização para evitar que o novo processo seja prejudicado por desinformações ou retaliações por alguns de seus membros;

f) Desenvolver estratégias de Logística Reversa: aqui as atenções devem estar voltadas para a criação das estratégias que alicerçarão a operação da nova atividade, garantindo a agregação de valor e incrementos na competitividade da empresa; 
g) Implementar as estratégias de Logística Reversa: nesta etapa final a atividade é colocada em prática com o objetivo de satisfazer as necessidades e expectativas dos clientes ao mesmo tempo que garanta a com rentabilidade para a empresa e acionistas. Por fim, tem-se o processo de feedback que garante a atualização permanente do ciclo de informações,impulsionando a flexibilidade da estratégia.

\subsection{Os desafios de Rogers e Tibben-Lembke (1999)}

Os autores levantaram os seguintes desafios para programas logísticos reversos:

a) Conflito Varejista: uma das dificuldades na gestão dos retornos consiste na diferença entre os objetivos de fabricantes e varejistas. Na devolução provocada pelo varejista pode haver desacordos com relação à condição do item ou a seu valor. Por outro lado, os fabricantes podem ser lentos nos acertos das devoluções com os varejistas. No final, ambas as partes precisam perceber a necessidade de desenvolver um trabalho de parceria com benefícios mútuos. Obviamente, também não pode viver sem o outro, eles precisam trabalhar juntos para reduzir o número de retornos e acelerar o tratamento dos que voltam. Ineficiências que alongam o tempo para o processamento de retonos podem causar danos a ambas as partes;

b) Sintomas de problemas nos retornos: aqui se encontram retornos não identificados ou não autorizados; longos tempos de ciclo no processamento dos retornos; processo de devolução com custos desconhecidos; perda de confiança de clientes na atividade; grande quantidade de retornos nos armazéns; entre outros;

c) Ausência de causa e efeito: o conhecimento da causa dos retornos se constitui em uma das mais importantes características de sistemas logísticos reversos e uma coleta de dados pobre leva a uma incerteza sobre as causas de retorno. No longo prazo, o resultado mais valioso das atividades reversas é o acúmulo de dados. Uma das questões mais importantes é ser capaz de acompanhar as causas dos retornos por meio de códigos. Geralmente, as empresas que gerenciam informações também gerir bem seus estoques de forma eficaz;

d) Resposta reativa: ao longo dos últimos anos, muitas empresas têm praticado logística reversa principalmente por causa da regulamentação do governo ou pressão dos órgãos ambientais, não necessariamente para alcançar um desenvolvimento econômico. Para a maioria dessas empresas, a logística reversa não tem sido tão fortemente enfatizada como outras atividades comerciais. Por este motivo, para muitas empresas não tem sido possível justificar um grande investimento na melhoria dos sistemas de logística reversa. 


\subsection{Interfaces da logística reversa com outros métodos}

De acordo com Barbieri (2007), o termo Gestão Ambiental pode ser aplicado a iniciativas administrativas e operacionais que tenham como objetivo a obtenção de resultados positivos sobre o meio ambiente tais como a redução ou a eliminação de danos causados pelas ações humanas e a prática de ações com o intuito de evitar a sua ocorrência. Jabbour et al (2009) reforçam o importante papel da Gestão Ambiental na mitigação dos efeitos negativos gerados pelas atividades empresariais, especialmente a partir do desenvolvimento de produtos e de processos ambientalmente adequados.

Assim, os resultados alcançados pela Logística Reversa possuem um forte viés com a Gestão Ambiental, uma vez que a captura de produtos e materiais e seu reaproveitamento ou reinserção nos processos produtivos auxiliam na questão da minimização da quantidade de produtos que podem deixar de ter o ambiente como seu destino final.

Já o chamado Ecodesign pode ser definido como um método para o desenvolvimento de produto cujo objetivo centra-se na minimização de seu do impacto ambiental, utilizando-se da criatividade para gerar produtos e processos mais eficientes em termos de sustentabilidade (KARLSSON e LUTTROPP, 2006). A escolha de materiais de baixo impacto ambiental, o desenvolvimento de produtos voltados à simplicidade e/ou modularidade, economia de energia para a fabricação dentre outros fatores fazem parte do rol de preocupações deste método. Desta maneira, a forte ênfase na minimização de impactos ambientais de um produto ao longo de seu ciclo de vida prevista por esta técnica relaciona-se amplamente com os conceitos de Logística Reversa aqui abordados já que o aproveitamento de um bem pode ser facilitado caso seu reaproveitamento seja previsto em suas etapas de concepção e desenvolvimento.

Para Barbieri (2007) a Produção Mais Limpa (PML) se refere a uma extensa abordagem de proteção ambiental, abrangendo todas as fases dos processos de manufatura (ciclo de vida do produto), com a finalidade de prevenção e de minimização, a curto e a longo prazos, dos riscos das atividades de processos a pessoas e ao meio ambiente. Desta maneira, esta técnica deve ser percebida como uma estratégia preventiva aplicada continuamente a processos, produtos e serviços. Assim, as ferramentas associadas à revisão de produtos e de seus processos visando a dirimir possíveis impactos ambientais existentes ou potenciais fazem com que a PML também possa proporcionar benefícios ao reaproveitamento de produtos pós-venda e pós-consumo (processos logísticos reversos externos) quanto de seus componentes ainda em processo (processos logísticos reversos internos). 


\section{Referencial metodológico proposto}

Para a construção de um referencial metodológico para a avaliação de desempenho de processos logísticos reversos de bens pós-venda em empresas industriais foram utilizados os elementos presentes nos trabalhos revisados citados no tópico anterior.

Os elementos foram divididos em nove categorias. A primeira delas trata de fatores relacionados ao desenvolvimento de produtos que podem contribuir para os processos logísticos reversos do bem após o sua saída da empresa produtora. Nesta categoria se encaixam a utilização de técnicas como o Ecodesign e a Produção Mais Limpa.

A segunda categoria diz respeito aos elementos relacionados aos processos de uma empresa que podem impactar positivamente na logística reversa pós- venda, tais como a adoção de um sistema de Gestão Ambiental e a utilização de técnicas produtivas que favoreçam o meio ambiente.

A terceira categoria se relaciona aos mecanismos adotados quando da entrada do produto no um processo logístico reverso. Aqui são considerados elementos como o conhecimento das razões da volta dos produtos e a clareza das políticas que regem os retornos adotadas por uma empresa.

Já os mecanismos de coleta dos produtos se constituem na quarta categoria considerada, estando aqui sua subdivisão entre a captação propriamente dita e o transporte. São considerados nesta categoria elementos como os locais de coleta, o acondicionamento dos produtos e os meios de transporte utilizados.

Os elementos que constituem a quinta categoria selecionada diz respeito aos mecanismos de recepção, triagem e armazenamento dos produtos. Estes processos são importantes tanto para a organização quanto para a preservação das condições físicas dos produtos retornados. Encaixam-se nesta categoria os procedimentos de seleção e destino e a existência de locais definidos para a guarda dos bens.

As sexta e sétimas categorias se relacionam ao processamento dos retornos e a sua disposição quando os mesmos não puderem ser reaproveitados dentro da própria empresa.

Por fim, nas categorias sistema de informação e sistema de coordenação se encaixam elementos que possam fornecer uma visão mais abrangente sobre a integração e a composição do sistema logístico reverso considerado. O Quadro 3 detalha os elementos considerados em cada categoria e faz uma referência aos autores consultados. 
Quadro 3 - Referencial metodológico para a avaliação do desempenho de processos logísticos reversos de bens pósvenda em empresas industriais

\begin{tabular}{|c|c|c|c|}
\hline \multicolumn{2}{|c|}{ CATEGORIA } & ELEMENTOS CONSIDERADOS & AUTORES \\
\hline \multirow{2}{*}{\multicolumn{2}{|c|}{ A) PRODUTOS }} & $\begin{array}{l}\text { 1. Uso de técnicas de desenvolvimento de } \\
\text { produto que favoreçam sua reutilização } \\
\text { (Ecodesign) }\end{array}$ & $\begin{array}{c}\text { De Britto e Decker (2002); de } \\
\text { Britto e Decker (2003); Grabara e } \\
\text { Kot (2009); Barker e Zabinski } \\
\text { (2008) }\end{array}$ \\
\hline & & $\begin{array}{l}\text { 2. Uso de técnicas de análise e modificação de } \\
\text { produto que favoreça sua reutilização } \\
\text { (Produção Mais Limpa) }\end{array}$ & Grabara e Kot (2009) \\
\hline \multirow{7}{*}{\multicolumn{2}{|c|}{ B) PROCESSOS }} & $\begin{array}{l}\text { 3. Planejamento prévio da rede logística de } \\
\text { retorno: procedimentos de retorno definidos }\end{array}$ & $\begin{array}{l}\text { Leite et al (2005); Ravi e Shankar } \\
\text { (2005); Barker e Zabinski (2008); } \\
\text { Lacerda (2002); Rodrigues (2009); } \\
\text { Rogers e Tibben-Lembke (1998) }\end{array}$ \\
\hline & & $\begin{array}{l}\text { 4. Conhecimento da principal motivação para } \\
\text { a adoção de processos reversos }\end{array}$ & $\begin{array}{l}\text { De Britto e Decker (2002); de } \\
\text { Britto e Decker (2003); Leite e } \\
\text { Zamith (2005); Ravi e Shankar } \\
\text { (2005) }\end{array}$ \\
\hline & & $\begin{array}{l}\text { 5. Conhecimento dos atores (devolutores, } \\
\text { receptores e processadores) e dos processos } \\
\text { envolvidos na Logística Reversa }\end{array}$ & $\begin{array}{c}\text { De Britto e Decker (2002); de } \\
\text { Britto e Decker (2003); } \\
\text { Rogers e Tibben-Lembke (1998) }\end{array}$ \\
\hline & & $\begin{array}{l}\text { 6. Conhecimento do tempo de ciclo do } \\
\text { processo }\end{array}$ & (Rogers e Tibben-Lembke (1998) \\
\hline & & $\begin{array}{l}\text { 7. Existência de mecanismos de Gestão } \\
\text { Ambiental }\end{array}$ & Grabara e Kot (2009)) \\
\hline & & $\begin{array}{c}\text { 8. Motivação ambiental para a adoção de } \\
\text { mecanismos de Logística Reversa }\end{array}$ & $\begin{array}{l}\text { Ravi e Shankar (2005); Grabara e } \\
\text { Kot (2009) }\end{array}$ \\
\hline & & $\begin{array}{l}\text { 9. Existência de técnicas produtivas que } \\
\text { favoreçam o meio ambiente (Produção Mais } \\
\text { Limpa) }\end{array}$ & (Grabara e Kot (2009) \\
\hline \multirow{7}{*}{\multicolumn{2}{|c|}{$\begin{array}{l}\text { C) ENTRADA - início dos } \\
\text { retornos }\end{array}$}} & $\begin{array}{l}\text { 10. Conhecimento das razões do retorno } \\
\text { (retornos de distribuição ou de clientes) }\end{array}$ & $\begin{array}{l}\text { De Britto e Decker (2002); de } \\
\text { Britto e Decker (2003); Rogers e } \\
\text { Tibben-Lembke (1998) }\end{array}$ \\
\hline & & $\begin{array}{l}\text { 11. Identificação das condições do produto } \\
\text { antes do retorno }\end{array}$ & $\begin{array}{l}\text { De Britto e Decker (2002); De } \\
\text { Britto e Decker (2003); Rogers e } \\
\text { Tibben-Lembke (1998) }\end{array}$ \\
\hline & & $\begin{array}{l}\text { 12. Padronização da identificação do possível } \\
\text { retorno }\end{array}$ & Lacerda (2002); Rodrigues (2009) \\
\hline & & $\begin{array}{l}\text { 13. Clareza das políticas e rotinas que regem o } \\
\text { retorno }\end{array}$ & $\begin{array}{c}\text { Genchev et al (2011); Rogers e } \\
\text { Tibben-Lembke (1998); De Britto } \\
\text { e Decker (2003) }\end{array}$ \\
\hline & & $\begin{array}{l}\text { 14. Identificação dos produtos retornados com } \\
\text { relação ao volume de vendas }\end{array}$ & Rogers e Tibben-Lembke (1998) \\
\hline & & $\begin{array}{l}\text { 15. Existência de serviço pós-venda (SAC, AT, } \\
\text { entre outros) }\end{array}$ & Genchev et al (2011) \\
\hline & & $\begin{array}{l}\text { 16. Existência de incentivos para a coleta de } \\
\text { produtos }\end{array}$ & Rogers e Tibben-Lembke (1998) \\
\hline \multirow{8}{*}{$\begin{array}{l}\text { D) } \\
\text { COLETA }\end{array}$} & \multirow{4}{*}{$\begin{array}{c}\text { D1) } \\
\text { CAPTAÇÃO }\end{array}$} & $\begin{array}{l}\text { 17. Padronização dos mecanismos de captação } \\
\text { de produtos - diretrizes de envio } \\
\text { estabelecidas e formalizadas }\end{array}$ & $\begin{array}{l}\text { Genchev et al (2011); Leite et al } \\
\text { (2005); Barker e Zabinski (2008) } \\
\text { Rogers e Tibben-Lembke (1998) }\end{array}$ \\
\hline & & 18. Definição prévia dos locais de coleta & Barker e Zabinski (2008) \\
\hline & & $\begin{array}{l}\text { 19. Identificação individual dos produtos/lotes } \\
\text { coletados }\end{array}$ & $\begin{array}{c}\text { Barker e Zabinski (2008) Rogers e } \\
\text { Tibben-Lembke (1998) }\end{array}$ \\
\hline & & $\begin{array}{c}\text { 20. Formalização dos processos por Notas } \\
\text { Fiscais de remessa }\end{array}$ & $\begin{array}{c}\text { De Britto e Decker (2003); } \\
\text { Lambert et al (2011) }\end{array}$ \\
\hline & \multirow{4}{*}{$\begin{array}{c}\text { D2) } \\
\text { TRANSPORTE }\end{array}$} & $\begin{array}{l}\text { 21. Padronização dos mecanismos de transporte } \\
\text { dos retornos }\end{array}$ & $\begin{array}{c}\text { Genchev et al (2011); Barker e } \\
\text { Zabinski (2008) }\end{array}$ \\
\hline & & $\begin{array}{l}\text { 22. Existência de meios de transporte e veículos } \\
\text { definidos }\end{array}$ & $\begin{array}{c}\text { Leite et al (2005); Barker e } \\
\text { Zabinski (2008) }\end{array}$ \\
\hline & & $\begin{array}{l}\text { 23. Frequência e trajeto de coletas definidos - } \\
\text { consolidação das coletas }\end{array}$ & Lambert et al (2011) \\
\hline & & 24. Acondicionamento do retorno definido & Leite et al (2005); Lambert et al \\
\hline
\end{tabular}




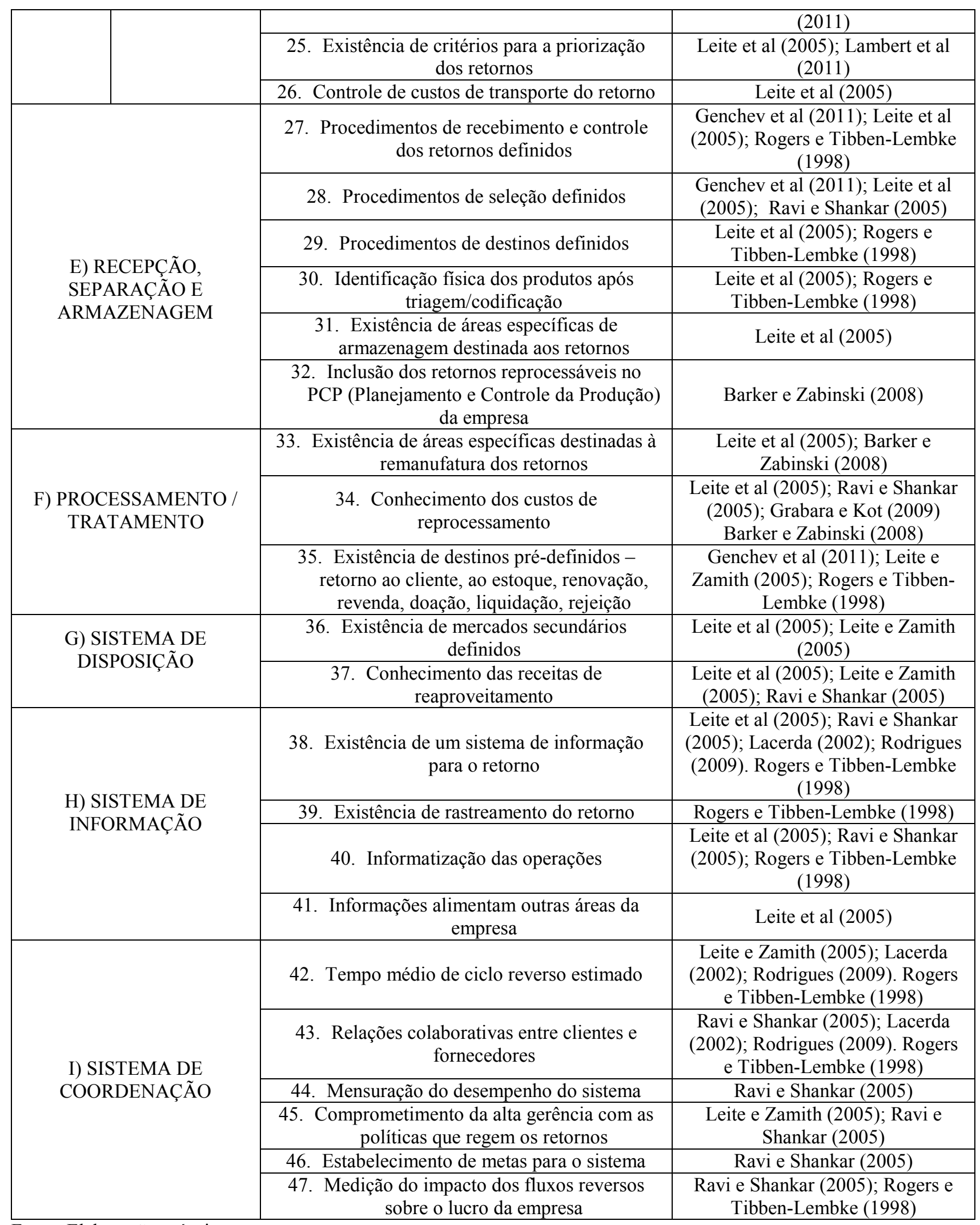

Fonte: Elaboração própria

Para tornar a medida mais objetiva, cada um dos aspectos elencados pode ser analisado considerando sua existência e intensidade em uma escala de três níveis:

a) Nível 0: nenhuma evidência de existência ou prática referente ao quesito avaliado;

b) Nível 1: fracas evidências de existência ou prática do quesito; 
c) Nível 2: claras evidências da existência e da prática do quesito avaliado.

É importante destacar que para algumas empresas algumas das categorias ou dos elementos elencados para a análise podem não ser aplicáveis. Este é o caso, por exemplo, das empresas que recolhem seus produtos pós-venda, mas, por alguma característica específica do produto, se vêem impossibilitadas de fazer sua recuperação em seu processo produtivo. Esta empresa apresentará inaplicabilidade da avaliação dos elementos relativos ao processamento dos retornos. Neste caso, deverá ser feita a desconsideração dos aspectos não aplicáveis à empresa.

\section{Exemplo de aplicação}

Este tópico trata da apresentação dos resultados da aplicação do referencial metodológico proposto em uma empresa so setor químico responsável pela fabricação de três linhas de produtos para plantas: produtos para proteção (defensivos agrícolas); produtos para nutrição (fertilizantes) e produtos específicos para jardinagem.

Seus principais clientes são distribuidores de produtos agropecuários, produtores rurais e empresas produtoras de produtos da mesma natureza que compram os produtos da empresa e revendem sob marca própria. A empresa é certificada pela norma ISO 9000:2008 desde o ano de 2008 e encontra-se atualmente em um processo inicial de estruturação para obtenção da certificação ISO 14000.

Para atendimento de seus clientes a empresa conta com uma equipe de 20 vendedores técnicos, formada por engenheiros agrônomos chamados pela empresa de Representantes Técnicos de Venda (RTV). Estes vendedores encontram sua atuação de vendas segmentada por regiões e a empresa possui seus produtos vendidos para todo o país.

A empresa possui processos logísticos reversos para produtos após a sua venda, estando entre as principais razões para as devoluções desacordos comerciais e problemas de qualidade nos produtos. É importante ressaltar que, por força de lei nacional, todo material utilizado para embalar diretamente agrotóxicos deve ser enviado para postos de coleta específicos presentes em todo o território nacional (Lei Federal 9974/2000). Assim, para esta empresa as embalagens desta natureza que contiveram os produtos retornados são enviadas a um dos postos de coleta apontados pelo INPEV (Instituto Nacional de Processamento de Embalagens Vazias). A Figura 1 sintetiza os fluxos reversos pós-venda da empresa. Este processo se inicia com o contato estabelecido pelo cliente que occore diretamente com a empresa (via A da Figura 1) ou por intermédio dos RTV (via B). Quando o contato é realizado por meio dos revendedores estes possuem a função de contatar a empresa participando-a da reclamação pronunciada (via C). Estes contatos são feitos tanto via email 
quanto por telefone e ao receber a reclamação a empresa inicia o preenchimento do chamado “Formulário de Reclamação do Cliente”, onde são incluídos os dados referentes à queixa.

Figura 1 - Fluxos reversos pós-venda da empresa

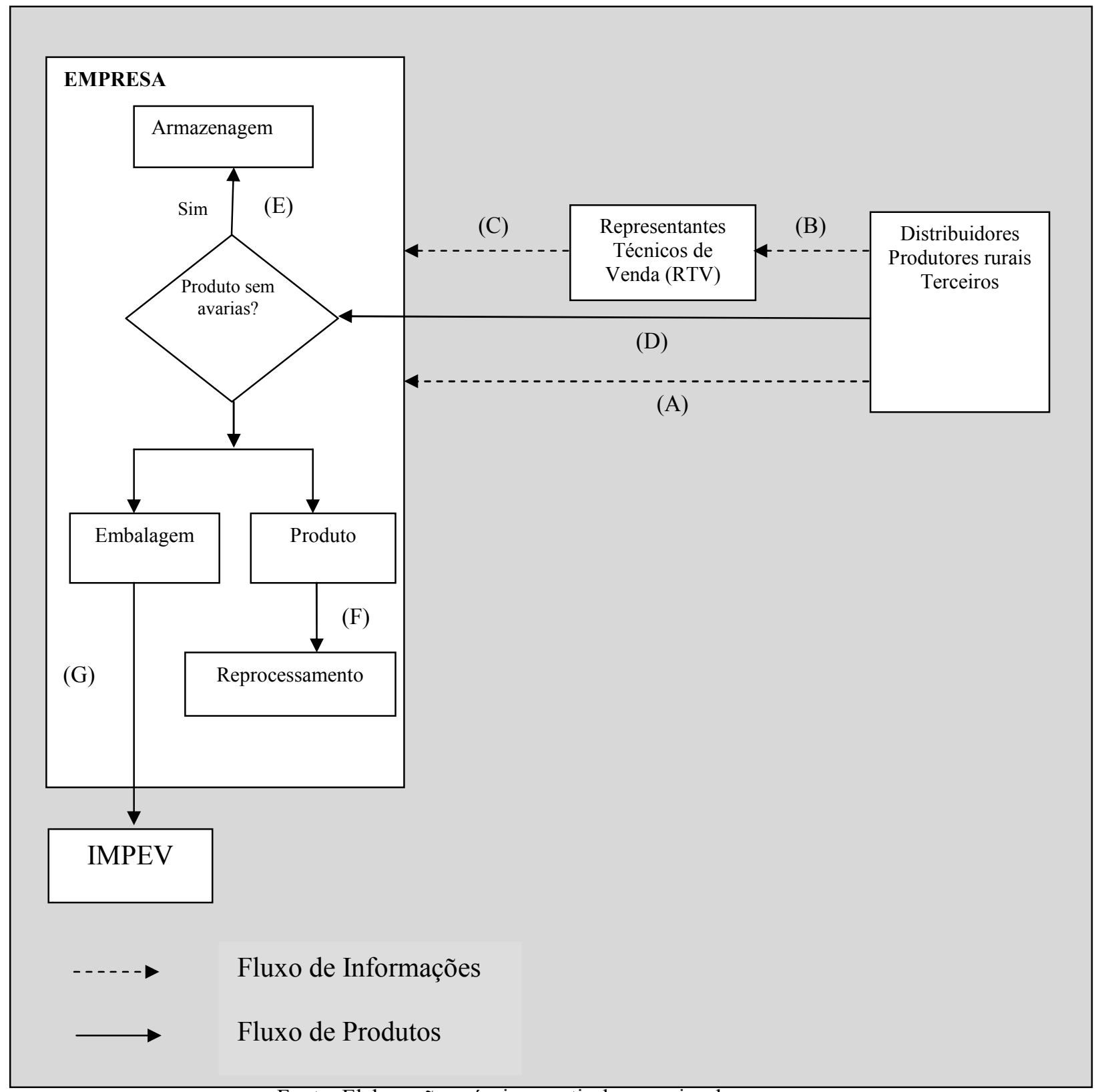

Fonte: Elaboração própria a partir de pesquisa de campo

Cópias deste formulário, juntamente com um número de protocolo gerado pela reclamação, são distribuídas ao cliente, ao setor de qualidade, aos possíveis responsáveis técnicos pela queixa registrada e para o responsável pelo setor de recebimento de materiais, a fim de participá-lo da posterior entrada do produto na empresa.

O produto em desacordo é retirado do cliente assim que for efetuada a próxima entrega (via D), quando também é feita a troca do produto reclamado por outro pertencente a um lote distinto. 
Para esta empresa as três razões de devolução são: desacordos comerciais, problemas de qualidade e problemas nas embalagens dos produtos.

As destinações dos produtos após o seu recolhimento são:

- Produtos devolvidos a partir de desacordos comerciais: os produtos são avaliados e reincorporados aos estoques da empresa (via E);

- Produtos devolvidos com problemas de qualidade: os produtos são avaliados para encontrar a divergência alegada e reaproveitados na produção de novos lotes de produtos (via F); quanto às suas embalagens, a embalagem que esteve em contato com agrotóxicos é enviada ao posto do INPEV do município de Guariba/SP (via $G$ ) e as embalagens que contiveram outros materiais são reaproveitadas no processo produtivo;

- Produtos com problemas nas embalagens: os produtos são reavaliados e as embalagens avariadas são trocadas, seguindo a mesma destinação anteriormente descrita.

\subsection{Desempenho dos processos logísticos reversos de produtos pós-venda}

Para a empresa, dentre as principais razões para a adoção do fluxo reverso de seus produtos encontra-se as pressões legais, principalmente relativas às embalagens de agrotóxicos vazias, e a consciência ambiental.

A empresa possui uma equipe de engenheiros agrônomos e químicos responsáveis tanto pelo desenvolvimento de seus produtos quanto pelo desenvolvimento de produtos para terceiros. $\mathrm{Na}$ empresa é possível verificar a utilização de técnicas que favorecem a utilização dos produtos após sua vida útil, sobretudo no caso de embalagens de alguns produtos, que são feitas de material reciclado, sendo também reciclável, o que permite sua reutilização.

Apesar de não haver formalização, a empresa possui forte foco ambiental que pode ser notado pela adoção de vários processos produtivos alternativos que favorecem o meio ambiente. Um exemplo disso se constitui no desenvolvimento e na adoção de um processo produtivo diferenciado para a produção de um fungicida com base em cobre que reduziu em $100 \%$ a utilização de combustível, em $70 \%$ a utilização de energia elétrica e em $50 \%$ a utilização de água. Este processo foi patenteado pela empresa e foi ganhador de vários prêmios como o Prêmio FINEP de Inovação Tecnológica no ano de 2007 e o Prêmio FIESP de Mérito Ambiental em 2011.

No seu processo logístico reverso pós-venda a empresa possui clareza em suas operações, graças principalmente à adoção de procedimentos formalizados que regem os retornos. A empresa possui conhecimento dos produtos retornados com relação a seu volume de vendas (em torno de $1 \%$ ) e apesar de não possuir um SAC ou rede de assistência técnica específica, a empresa consegue prover um feedback apurado sobre seus retornos a seus clientes. Isto porque, além do preenchimento imediato de um formulário específico que segue a reclamação, a empresa também 
gera um número de protocolo que permite aos clientes saber a qualquer momento a posição da empresa em relação aos produtos reclamados.

Com relação ao incentivo para a coleta de produtos, este aspecto não foi considerado aplicável à empresa em questão, pois o início dos retornos não carece de incentivos já que os retornos são gerados expontaneamente pelas razões já expostas.

A coleta dos produtos também é formalizada, embora não haja identificação individual dos lotes coletados. Os processos são formalizados sob Notas Fiscais de devolução de produtos. Quanto ao transporte, a empresa possui um caminhão próprio que se encarrega de parte de suas entregas e recolhimento de mercadorias. Porém, quando observados altos volumes de retornos a empresa necessita recorrer a empresas de transporte terceirizadas (transportadoras). Não há consolidação de coletas e a empresa possui identificados os custos relacionados ao transporte de retorno.

São também definidos e formalizados os procedimentos de recebimento, seleção e destinação dos produtos, que são identificados após a triagem e armazenados em espaços específicos de acordo com sua destinação. Os materiais reprocessáveis são inseridos no PCP da empresa e o reprocessamento é realizado diretamente nos processos produtivos e os custos do reprocessamento são conhecidos.

Quanto a seu sistema de disposição, a empresa possui uma empresa de reciclagem definida para os produtos não reaproveitáveis na empresa, tais como embalagens de plástico e papelão. Para o gerenciamento destes materiais a empresa formou uma equipe com representantes de vários de seus setores que possui como atribuições o gerenciamento e a venda de das embalagens, sendo as verbas arrecadadas com estes repasses utilizadas pelos membros da comissão em eventos comemorativos da empresa, tais como os festejos do Dia do Trabalho.

Assim como todas as informações da empresa, os fluxos relativos aos retornos são incluídos em seu sistema ERP sendo, portanto, totalmente informatizados e de acesso aberto aos setores da empresa que possuem interesse nas informações relativas aos retornos.

O sistema reverso não possui seu tempo médio estimado, mas a empresa opera com indicadores para a mensuração de outras características, tal como o impacto do fluxo reverso sobre o lucro da empresa, e há o estabelecimento claro de metas para o sistema em seu planejamento estratégico.

A Tabela 1 resume a pontusção atingida pela empresa com relação à sua logística Reversa de produtos pós-venda. 
Tabela 1 - Pontuação atingida pela empresa para seus processos logísticos reversos pós-venda por categorias

\begin{tabular}{|c|c|c|c|}
\hline Categoria & $\begin{array}{c}\text { Pontuação máxima } \\
\text { dos aspectos aplicáveis }\end{array}$ & Pontuação atingida & \% \\
\hline Produtos & 4 & 4 & $100,0 \%$ \\
\hline Processos & 14 & 9 & $64,2 \%$ \\
\hline Entrada & 12 & 10 & $83,3 \%$ \\
\hline Coleta & 20 & 10 & $50,0 \%$ \\
\hline Recepção/Triagem/Armazenamento & 12 & 12 & $100,0 \%$ \\
\hline Processamento/Tratamento & 6 & 4 & $66,7 \%$ \\
\hline Sistema de disposição & 4 & 4 & $100,0 \%$ \\
\hline Sistema de informação & 8 & 8 & $100,0 \%$ \\
\hline Sistema de coordenação & 12 & 10 & $83,3 \%$ \\
\hline TOTAL & $\mathbf{9 2}$ & $\mathbf{7 1}$ & $\mathbf{7 7 , 2} \%$ \\
\hline
\end{tabular}

Fonte: Elaboração própria

\section{Considerações finais}

Visando ao atendimento a demandas ambientais ou objetivando benefícios econômicos ou na imagem da empresa, nota-se um paulatino crescimento da utilização da Logística Reversa tanto de bens pós-venda quanto de bens pós-consumo dentro das operações das empresas industriais. Isto se comprova pelo aumento do interesse de empresas e de estudiosos pelo assunto, fator que consagra as operações relativas à Logística Reversa dentro do rol das atividades empresariais.

Assim, como em outros processos da empresa, as atividades praticadas pela Logística Reversa devem ser avaliadas e mensuradas, de maneira a possibilitar a promoção de melhorias em seu desempenho.

Neste sentido, procurando auxiliar as empresas industriais na tarefa de avaliar o desempenho de processos logísticos reversos de produtos pós-venda, este artigo teve por objetivo a construção de um referencial metodológico específico, desenvolvido a partir de parâmetros da literatura indicados por autores diversos para a construção e sistematização da Logística Reversa.

O referencial foi desenvolvido tendo como base nove categorias de parâmetros (elementos), selecionados de modo a tornar a avaliação ampla a partir do envolvimento 47 características que podem permear os processos reversos.

A partir da aplicação do referido referencial em uma empresa do setor químico, foi possível atestar sua aplicabilidade em empresas industriais e notar que, além de fornecer um panorama dos processos logísticos reversos de uma empresa, indicando os possíveis pontos de melhoria, os elementos do referencial metodológico criado podem ser utilizados como indicadores para a avaliação de investimentos realizados em favor da melhoria do sistema. Ressalta-se ainda a possibilidade de utilização da avaliação porporcionada pelo referencial criado para a comparação do desempenho dos processos logísticos reversos entre empresas distintas. 


\begin{abstract}
In order to meet the new demands of the market or even to host economic objectives, companies have sought their environmental suitability from changing their production systems towards the adoption of cleaner technologies and the study of the environmental impacts of their products. Thus, the reintegration of materials in the production process and reuse of post- sale or post-consumer products have been increasingly practiced. To this end, new administrative activities shall be conducted, highlighting the Reverse Logistics, which deals with the planning, operations and information needed to material reuse or proper disposal of returned products to companies producing systems. Given this context, the aim of this paper is to construct a qualitative methodological framework for evaluating the performance of processes of reverse logistics of "after-sale assets" adopted by industrial companies. As a result, the methodological framework development considered nine categories of elements related to returns that enabled the intended evaluation, namely: products; processes; input mechanisms; collection mechanisms; mechanisms for receiving, sorting and storage; mechanisms for processing of returns; layout system; information systems; and coordination system. For examples of the application of the proposed methodological framework, a survey was conducted in a chemical company that showed satisfaction in $77.2 \%$ of the elements considered.
\end{abstract}

Key-words: reverse logistics; after-sales assets; performance; industry.

\title{
Referências
}

BARBIERI, J. C. Gestão ambiental empresarial: conceitos, modelos e instrumentos. São Paulo: Saraiva, 2007. 2. ed.

BARKER, T. J.; ZABINSKY, Z. B. Reverse logistics network design: a framework for decision making. Proceedings of the 2008 Industrial Engineering Research Conference. Vancouver, 2008, p. 1290-1295.

BARKER, T. J.; ZABINSKY, Z. B. A multicriteria decision making model for reverse logistics using analytical hierarchy process. Omega, n. 39, 2011, pp.558-573.

CHAVES, G. L. D.; ALCÂNTARA, R. L. C.; ASSUMPÇÃO, M. R. P. Medidas de desempenho na Logística Reversa: o caso de uma empresa do setor de bebidas. Relatórios de pesquisa em Engenharia de Produção, v. 8, n. 2, 2008, p. 123.

CHAVES, G.; BARBOSA, J. R.; ALCÂNTARA, R. L. C. Medidas de desempenho para avaliação da Logística Reversa. In: Anais do XXXI Encontro Nacional de Engenharia de Produção. Belo Horizonte/MG: ABEPRO, 2011.

DE BRITO, M. P.; DEKKER, R. Reverse logistics: a framework. The Netherlands: Erasmus University Rotterdam, 2002 .

DE BRITO, M. P.; DEKKER, R. A Framework for Reverse Logistics. ERIM Report Series Research in Management. Rotterdam: Erasmus Research Institute of Management, 2003.

EL KORCHI, A.; MILLET, D. Designing a sustainable reverse logistics channel: the 18 generic structures framework. Journal of Cleaner Production, n. 19, 2011, p. 588-597.

GENCHEV, S. E.; RICHEY, R. G.; GABLER, C. B. Evaluating reverse logistics programs: a suggested process formalization. The International Journal of Logistics Management, v. 22, n. 2, 2011, p. 242-263. crossref

GIACOBO, F.; ESTRADA, R. J. S.; CERETTA, P. S. Logística Reversa: a satisfação do cliente no pós-venda. Revista Eletrônica de Administração, v. 9, n. 5, 2003.

GRABARA, J. K.; KOT, S. Theoretical frames for deseigning Reverse Logistics processes. Review of General Management, v. 9, p. 55-61, 2009.

JABBOUR, C. J. C.; SANTOS, F. C. A. Sob os ventos da mudança climática: desafios, oportunidades e o papel da função produção no contexto do aquecimento global. Gestão \& Produção, v. 16, n. 1, p. 111-120, 2009. cross ref 
KARLSSON, R.; LUTTROPP, C. Ecodesign: what's happening? An overview of the subject area of Ecodesign and the papers in this special issue. Journal of Cleaner Production, v. 14, 2006, p. 1291-1298. cross ref

KINLAW, D. C. Empresa competitiva e ecológica. São Paulo: Makron Books, 1997.

LACERDA, L. Logística Reversa: uma visão sobre os conceitos básicos e as práticas operacionais. Rio de Janeiro: COPPEAD/UFRJ, 2002.

LAMBERT, S.; RIOPEL, D.; ABDUL-KADER, W. A Reverse Logistics decisions conceptual framework. Computers \& Industrial Engineering, 2011, crossref

LEITE, P. R.; ZAMITH, E. P. Logística Reversa de produtos não consumidos: práticas de empresas no Brasil. Revista Gestão Organizacional, v. 3, n. 3, 2005.

LEITE, P. R.; BRITO, E. P. Z; MACAU, F. R.; PÓVOA, A. C. Determinantes da estruturação dos canais reversos: o papel dos ganhos econômicos e de imagem corporativa. In: Anais... XXIX Encontro da AMPAD (EnANPAD). Brasília: ANPAD, 2005.

LEITE, P. R. Logística Reversa: meio ambiente e competitividade. São Paulo: Pearson Prentice Hall, 2. ed., 2009.

LIVA, P. B. G.; PONTELO, V. S. L.; OLIVEIRA, W. S. Logística Reversa. Gestão e Tecnologia Industrial. IETEC, 2003.

MOLlENKOPF, D. A.; CLOSS, D. J. The hidden value in reverse logistics. Supply Chain Management Review, v. 9 , n. 5, p. 34-43, 2005.

RAVI, V.; SHANKAR, R. Analysis of interactions among the barriers of reverse logistics. Technological Forecasting \& Social Change, n. 72, 2005, p. 1011-1029.

RODRIGUES, D. F.; RODRIGUES, G. G.; LEAL, J. E.; PIZZOLATO, N. D. Logística Reversa: conceitos e componentes do sistema. In: Anais... XXII Encontro Nacional de Engenharia de Produção (ENEGEP). Curitiba: PUCPR, 2002.

RODRIGUES, A. M.; REBELATO, M. G.; RODRIGUES, I. C.; SANTOS, M. M. Logística Reversa de residuos industriais: estudo de caso em uma empresa procesadora de alimentos. In: Anais do XXIX Encontro Nacional de Engenharia de Produção (ENEGEP). Salvador/BA: ABEPRO, 2009.

RODRIGUES, A. M.; REBELATO, PEJON, L. B. Elaboração de um roteiro metodológico qualitativo para auditoria de procesos logísticos reversos em empresas industriais. In: Anais do XXXII Encontro Nacional de Engenharia de Produção (ENEGEP). Bento Gonçalves/RS: ABEPRO, 2012.

ROGERS, D. S.; TIBBEN-LEMBKE, R. S. Going backwards: Reverse Logistics trends and pratices. The University of Nevada, Reno, Center for Logistics Management, Reverse Logistics Concil, 1999.

STOCK, J. R. The Development and Implementation of Reverse Logistics Programs. Oakbrook, IL: Council of Logistics Management, 1998.

WU, Y. J.; CHENG, W. Reverse logistics in the publishing industry: China, Hong Kong and Taiwan. International Journal of Physical Distribution \& Logistics Management, v. 36, n.7, p. 507-523, 2006. cross ref

XAVIER, L. H.; VALLE, R.; GABBAY, A. A logística e a gestão ambiental: convergência para o sucesso organizacional. In: Anais do VII Simpósio de Administração da Produção, Logística e Operações Internacionais (SIMPOI). São Paulo: FGV, 2004.

\section{Dados dos autores}

Nome completo: Andréia Marize Rodrigues

Filiação institucional: FCAV - UNESP - Jaboticabal/SP

Departamento: Economia Rural 
Função ou cargo ocupado: Professora

Endereço completo para correspondência (bairro, cidade, estado, país e CEP): Via de Acesso Prof.

Donato Castellane s/n - 14884-900 - Jaboticabal - SP

e-mail: andreiamarize@fcav.unesp.br

Nome completo: Marcelo Giroto Rebelato

Filiação institucional: FCAV - UNESP - Jaboticabal/SP

Departamento: Economia Rural

Função ou cargo ocupado: Professor

Endereço completo para correspondência (bairro, cidade, estado, país e CEP): Via de Acesso Prof.

Donato Castellane s/n - 14884-900 - Jaboticabal - SP

e-mail:mgiroto@fcav.unesp.br

Submetido em: 21/02/2011

Aceito em: 22/10/2014 